\title{
A BUSCA PELA EFETIVIDADE DAS NORMAS RELATIVAS A REPARTIÇÃO E UTILIZAÇÃO DOS CURSOS DE ÁGUAS INTERNACIONAIS
}

\author{
Alice Rocha \\ Júlia Motte-Baumvol*
}

\section{Introdução}

Um curso de água pode ser definido como um grande rio (reconhecido pelo número de seus afluentes, a importância de seu débito, a extensão de seu curso)”1 Tal definição contém em sim mesma, de modo quase automático, um caráter internacional pois os elementos presentes no parêntese desta prevêem o encontro inevitável de várias soberanias territoriais. De fato, o curso de água internacional engloba as “águas da superfície localizadas no território de mais de um Estado, podendo compreender os afluentes situados sobre o território de mais de um Estado, e até mesmo canais laterais.”2

Independentemente da terminologia utilizada para definir tal espaço - "curso de águas internacionais”, “rio internacional” ou “bacia de drenagem internacional” - é possível constatar com facilidade que os conflitos relacionados à água nestes espaços são freqüentes, tendo em vista que um mesmo curso fluvial atravessa vários Estados - vizinhos, em amonte ou em aval - deixando estes dependentes daqueles para repartir e gerir o mesmo recurso natural.

Se, de um lado, os problemas relativos à navegação em rios internacionais foram amplamente resolvidos desde 1815, ano em que se deu o primeiro tratado sobre a matéria, estabelecendo um princípio geral de liberdade de tratamento, por outro lado, resta a questão de saber como dois Estados devem dividir e utilizar o recurso natural comum. Isto porque, se

\footnotetext{
* Mestre em Direito pelo Centro Universitário de Brasília - UniCEUB e doutoranda em Direito na Université Aix-Marseille III, na França. E-mail: rochaalice@yahoo.com.br

* Mestre em Direito pela Université de Paris II Panthéon-Assas e doutoranda em Direito na Université de Paris I Panthéon-Sorbonne. E-mail: julia.mottebaumvol@gmail.com

${ }^{1}$ Do original, “[...] une grande rivière (remarquable par le nombre de ses affluents, l'importance de son débit, la longueur de son cours)” Le Petit Robert. Dictionnaires Le Robert : Paris, 1997, 2264 p.

2 Do original, “[...] les eaux de surface mouvantes localisées dans le territoire de plus d'un Etat et pouvant comprendre les affluents situés sur le territoire de plus d'un Etat, voire des canaux latéraux.” SALMON, J. Dictionnaire de droit international public. Bruxelas: Bruylant, 2001, p.506. Este mesmo dicionário ainda especifica que “[...] la notion de fleuve international a beaucoup perdu de son importance dans le droit contemporain. Celui-ci donne la préférence aux concepts plus étendus de cours d'eau international et de bassin de drainage international, sauf lorsqu'il s'agit de frontières tracées dans des fleuves successifs."
} 
todo Estado é soberano em relação à água dentro de seu território ${ }^{3}$, deve ser esclarecido que esta soberania não é absoluta, sendo limitada pelas obrigações impostas pelo direito internacional $^{4}$. Assim sendo, cabe a este direito internacional a função de criar normas destinadas à repartição e à utilização industrial, agrícola ou humana deste recurso natural, possuindo uma implicância direta na determinação e proteção da qualidade das águas comuns divididas.

Objetivando determinar como este recurso natural será repartido e utilizado, tais normas internacionais são formuladas de modo abrangente, a partir da utilização de princípios nem sempre muito tangíveis, como a razoabilidade e equidade. Associado a isto, tais dispositivos constituem-se a partir de termos sem precisão e com viés subjetivo como “substancial”. A imprecisão destes termos e princípios, assim como a amplitude de interpretação oferecida aos Estados, faz surgir uma série de conflitos de entendimentos entre os Estados que acarretam um enfraquecimento da efetividade destas normas.

A proposta do presente estudo será justamente analisar os instrumentos utilizados pelos Estados e aplicadores de tais normas internacionais na busca pela efetividade destas, partindo do pressuposto de que a utilização da via judicial para o esclarecimento do sentido dos dispositivos estabelecidos na norma não é o caminho mais recomendado para a busca da efetividade da mesma. Por isso, novos instrumentos são oferecidos como meios de alcance da chamada "eficácia social” 5 das normas relativas à utilização e repartição dos cursos de águas internacionais.

Em um primeiro momento, serão determinadas as obrigações relativas a repartição e utilização do curso de águas internacionais, demonstrando o fenômeno da proliferação do contencioso na busca de efetividade destas normas. Para tanto, serão utilizadas diversas fontes do direito internacional, como as Regras de Helsinki (1966), adotadas pela Associação de Direito Internacional (International Law Association), as Declarações de Estocolmo (1972) e do Rio de Janeiro (1992) e a Convenção de Nova Iorque de 1997 sobre a utilização dos rios internacionais (Convenção de 1997), adotada quase que de forma unânime pela Assembléia

\footnotetext{
${ }^{3}$ HIGGINS, R. Problems and Process : International law and how we use it. Oxford: Oxford University Press, 1994, p.134

${ }^{4}$ BROMS, B. Natural Resources, sovereignty over. In: BERNHARDT, R. (ed.), Encyclopaedia of Public International Law. Londres: North-Holland, 1997, vol. 3, p. 523.

${ }^{5}$ O termo efetividade é entendido por alguns autores como "eficácia social”, tendo em vista que esta se dá quando ocorre o cumprimento de modo efetivo das normas legais por parte da sociedade, que além de reconhecer as normas, as cumprem, momento em que os comandos e preceitos normativos efetivamente incidem na vida social. BARROSO, L. O Direito Constitucional e a Efetividade de suas Normas: limites e possibilidades da Constituição Brasileira. 7. ed. Rio de Janeiro: Renovar, 2003, p. 84.
} 
Geral das Nações Unidas mas que não está em vigor. Além destas fontes, serão utilizados dois tratados bilaterais (o Tratado entre os Estados-Unidos e o México de 3 de fevereiro de 1944 em relação ao Rio Grande e os Acordos de Charleville-Mézières de 26 de abril de 1994 sobre o rio Escaut e o rio Meuse) com o objetivo de mostrar a prática estatal contemporânea.

Em um segundo momento, serão analisados os novos instrumentos utilizados na busca da efetividade das normas relativas à utilização e a repartição dos cursos de água internacionais. Esses novos instrumentos são tanto de caráter legal, como a utilização do princípio da cooperação para interpretação dos dispositivos normativos, como institucionais, momento em que serão analisadas as Comissões Internacionais.

Vale ressaltar que o conceito de efetividade utilizado neste estudo se caracteriza como a realidade do direito, demonstrada a partir da coincidência entre o comportamento social e os modelos traçados pela norma jurídica. ${ }^{6}$ Tal efetividade se aproxima do conceito de eficácia, mas não se confunde com esta que ocorrendo em um momento anterior é a responsável por oferecer aptidão às normas de produzirem efeitos próprios, conferindo às mesmas as qualidades necessárias para ser aplicada, exigida e executada. ${ }^{7}$

\section{A falta de efetividade das normas materiais relativas à utilização dos cursos de água internacionais}

\subsection{Apresentação das normas materiais}

A partir da leitura da doutrina e da jurisprudência em direito internacional, percebe-se que existem duas normas principais na matéria: primeiramente, a obrigação de utilizar os cursos de água internacionais de modo equitável e razoável e, em segundo lugar, a obrigação de não causar dano significativo ao mesmo.

\subsubsection{A utilização equitável e razoável dos cursos de águas internacionais}

Um conflito de usos dos cursos de águas internacionais ocorre quando o volume ou a qualidade da água de um curso de água internacional dado se dão de modo a não permitir a todos os Estados com território ao longo deste curso de obter a utilização plena que estes consideram razoável e útel. Diante deste conflito, resta o questionamento a respeito de como

\footnotetext{
${ }^{6}$ MELLO, M. Teoria do Fato Jurídico: plano da validade. 3. ed., vol. 1, São Paulo: Saraiva, 1999, p. 13-14.

7 BARROSO, L. $\boldsymbol{O}$ Direito Constitucional e a Efetividade de suas Normas: limites e possibilidades da Constituição Brasileira. 7. ed, Rio de Janeiro: Renovar, 2003, p. 83.
} 
realizar a divisão ou repartição ${ }^{8}$ da utilização destas águas. De acordo com a Comissão do Direito Internacional (CDI), “o princípio da igualdade soberana do Estado quer que qualquer Estado do curso de água tenha, sobre a utilização do curso de água, direitos qualitativamente iguais e correlativamente ligados aos dos outros Estados do curso de água”9 No entanto, não se deve concluir, com base neste princípio, que cada Estado do curso de água tem direito à partes e vantagens iguais. Este princípio também não significa que as águas devem ser divididas de modo idêntico. ${ }^{10} \mathrm{O}$ que deve ser compreendido é que cada Estado do curso de água tem o direito de utilizá-lo e de obter todas as vantagens de modo equitável ${ }^{11}$.

Nascida nos Estados Unidos, a partir das sentenças da Corte Suprema sobre os litígios interestatais do início do século XX, a doutrina da utilização equitável é amplamente utilizada como regra geral de direito aplicável à determinação dos direitos e das obrigações dos Estados. ${ }^{12}$ Já em 1929, o Corte Permanente de Justiça Internacional, a propósito da navegação sobre o rio Oder, declarou que:

[...] a comunidade de interesses sobre um rio navegável torna-se a base de uma comunidade de direito, da qual os traços essenciais são a perfeita igualdade dos Estados ribeirinhos no uso de todo o percurso do rio e a exclusão de todo privilégio de qualquer residente em relação aos outros. ${ }^{13}$

A partir desta doutrina, surge o princípio da utilização equitável e razoável, erigido pela Convenção de Nova Iorque de 1997 como o princípio base da utilização dos cursos de águas internacionais. Isto está disposto de modo claro em seu artigo $5^{\circ}$, que determina que os Estados do curso de água devem utilizá-lo de maneira equitável e razoável. Em especial, o artigo dispõe que um curso de água internacional será utilizado e considerado a partir de uma visão de alcance de vantagens ótimas e compatíveis com as exigências de uma proteção adequada deste. Para isso, o artigo $6^{\circ}$ desta mesma Convenção indica como os Estados devem proceder, enunciando que:

\footnotetext{
${ }^{8}$ Para o presente artigo, repartição e distribuição serão utilizados no mesmo sentido.

${ }^{9}$ Do original, "le principe de l'égalité souveraine de l'Etat veut que tout Etat du cours d'eau ait, sur l'utilisation du cours d'eau, des droits qualitativement égaux et corrélativement liés à ceux des autres Etats du cours d'eau" Nações Unidas. Annuaire de la Commission du Droit International, 1994, vol. 2, segunda parte, p.103.

${ }^{10}$ HIGGINS, R. Problems and Process : International law and how we use it. Oxford: Oxford University Press, 1994, p.134

${ }^{11}$ Ibidem.

${ }^{12}$ SETTE-CAMARA, J. Pollution of International Rivers. In : Recueil des Cours de l'Académie de Droit International de la Haye, 1984, vol. 3, p. 119.

${ }^{13}$ Do original, "[...] la communauté d'intérêts sur un fleuve navigable devient la base d'une communauté de droit, dont les traits essentiels sont la parfaite égalité de tous les Etats riverains dans l'usage de tout le parcours du fleuve et l'exclusion de tout le privilège d'un riverain quelconque par rapport aux autres" Juridiction territoriale de la Commission internationale de l'Oder (Tchécoslovaquie, Danemark, France, Allemagne, Royaume-Uni, Suède, Pologne), CPIJ, Série A, decisão n 23, p.27.
} 
[...] a utilização equitável e razoável [...] implica na consideração de todos os fatores e circunstâncias pertinentes, principalmente: os fatores geográficos, hidrográficos [...], as necessidades econômicas e sociais [...] os efeitos da utilização sobre outros Estados do curso de água [...] etc..

No entanto, a própria CDI ressalta que:

Esta regra (artigo $6^{\circ}$ ) sendo necessariamente geral e flexível, exige para sua boa aplicação, que os Estados tenham em conta os fatores concretos e próprios ao curso de água internacionais de que trata, bem como as necessidades e utilizações dos Estados do curso de água interessados ${ }^{14}$.

Além disso, a lista de fatores do artigo $6^{\circ}$ a ser considerada tem um caráter indicativo e não limitativo. Isto se deve ao fato de que, de acordo com o CDI, “a extrema diversidade dos cursos de águas internacionais e as necessidades humanas às quais respondem proíbem de fato o estabelecimento de uma lista completa destes fatores que podem ser relevantes em cada caso”. ${ }^{15}$

Por outro lado, a segunda frase do $\S 1^{\circ}$ do artigo $5^{\circ}$ da Convenção, estipula que os Estados devem chegar a um resultado ótimo em matéria de utilização das vantagens. Isto significa que os Estados do curso de água buscam as maiores vantagens possíveis e agem de modo a conciliar suas necessidades ao mínimo de prejuízos. ${ }^{16}$ A CDI indica que para o alcance desta situação ótima de utilização e de vantagens, deve ser levada em consideração ainda a compatibilidade com as exigências de um proteção adequada do curso de água internacional. $^{17}$ Através destas disposições, a Convenção de 1997 busca sublinhar o reconhecimento dos direitos das partes à utilização e as vantagens do curso de água internacional, direitos que são iguais no seu princípio e correlacionados em sua aplicação.

\subsubsection{A obrigação de não causar dano significativo ao curso de água internacional}

\footnotetext{
${ }^{14}$ Do original, "L’utilisation équitable et raisonnable [...] implique la prise en considération de tous les facteurs et circonstances pertinents, notamment: les facteurs géographiques, hydrographiques [...], les besoins économiques et sociaux [...] les effets de l'utilisation sur d'autres Etats du cours d'eau [...], etc. E “ Cette règle (de l'article 6) étant nécessairement générale et souple, sa bonne application exige que les Etats tiennent compte des facteurs concrets et propres au cours d'eau international dont il s'agit, ainsi que des besoins et des utilisations des Etats du cours d'eau intéressés". Nações Unidas. Annuaire de Ia Commission du Droit International, 1994, vol. 2, p.107.

15 Do original, “l'extrême diversité des cours d'eau internationaux et des besoins humains auxquels ils répondent interdit en effet d'établir une liste complète de ces facteurs qui pourraient être pertinents dans chaque cas” Nations Unies, Annuaire de la Commission du Droit International, 1994, vol. 2, p.107.

${ }^{16}$ CAFLISCH, L. La convention du 21 mai 1997 sur l'utilisation des cours d'eau internationaux à des fins autres que la navigation. In : Annuaire français de droit international, 1997, p. 761.

${ }^{17}$ Nações Unidas. Annuaire de la Commission du Droit International, 1994, vol. 2, p.104.
} 
A obrigação de não causar dano significativo ao curso de água internacional é subordinada ao princípio mesmo de utilização equitável e razoável, e implica um dever de diligência da parte do Estados.

\subsubsection{Uma obrigação subordinada ao princípio da utilização equitável e razoável}

A proteção e a preservação dos cursos de águas internacionais inscrevem-se no âmbito mais vasto da salvaguarda do meio ambiente global. O problema se apresenta com maior profundidade em relação aos cursos de águas internacionais, freqüentemente situados no centro de regiões muito povoados, sendo recursos indispensáveis à sobrevivência das populações ribeirinhas. Um dos problemas desta utilização pelas populações à margem do rio é o aumento da salinização das águas causado pelas atividades de irrigação. Além disso, existe ainda a questão da exploração das águas pelos Estados situados na parte superior do curso para fins de produção de energia elétrica que pode temporariamente privar de água o Estado situado abaixo do curso (Estado de aval), sendo que este ao mesmo tempo pode causar inundações ao território daquele, caso proceda à retenção deste mesmo curso. Tais situações podem ainda prejudicar a fauna e a flora das regiões, assim como o próprio consumo humano do recurso. ${ }^{18}$

Tais situações podem ser administradas pela adoção da doutrina Harmon da soberania territorial absoluta, que permite à cada Estado do curso de água internacional utilizar a água compartilhada da maneira que achar conveniente. No entanto, paralelamente a este direito à soberania absoluta, existe o direito do Estado de não sofrer prejuízos. De fato, todo Estado possui o direito que o seu território seja respeitado, não havendo razão para a deteriorização de seu meio ambiente em virtude de atos provenientes de outros Estados. O direito de preservação de seu próprio território não é menos absoluto do que o do Estado poluente de utilizar as águas que passam pelo seu território ${ }^{19}$. A partir deste entendimento, desenvolveu-se a prática contemporânea de acordo com a regra sic utere tuo ut alienum non laedas (utilize o teu de maneira a não causar um prejuízo ao outro).

Entretanto, se de acordo com esta prática não se deve causar prejuízo ao outro, deve ser considerado em paralelo que tal proibição não é absoluta. Em relação a isto, constata-

\footnotetext{
${ }^{18}$ CAFLISCH, L. Règles générales du droit des cours d'eaux internationaux. In : Recueil des Cours de l'Académie de Droit International de la Haye, 1989, VII, p. 163.

${ }^{19}$ KISS, A. BEURIER, J-P. Droit International de l'Environnement, Paris : Pedone, 2004, p. 235.
} 
se uma evolução deste princípio que pode ser ilustrado com a Declaração de Estocolmo de 1972 e a recente Convenção de Nova Iorque dos 1997. De acordo com o Princípio 21 da Declaração de Estocolmo, “Os Estados têm o direito soberano de explorar os seus próprios recursos [...] e têm o dever de fazer de modo que as atividades exercidas nos limites da sua jurisdição não causem prejuízo ao meio ambiente de outros Estados”, ou seja, é proibido qualquer espécie de prejuízo causado por um Estado ao meio ambiente de outro Estado. Todavia, o artigo $7^{\circ}$ da Convenção de Nova Iorque de 1997, adotado vinte anos após a Declaração de Estocolmo, modifica esta proibição geral. $\mathrm{O}$ artigo $7^{\circ}$ dispõe que "os Estados do curso de água devem aplicar todas as diligências necessárias para utilizar o curso de água internacional de maneira a não causar prejuízos significativos aos outros Estados do curso de água”.

Os Acordos de Charleville-Mézières de 26 de Abril de 1994 seguem esta lógica. Vê-se, por exemplo, que pelo artigo $3^{\circ} \S 2^{\circ}$, alínea “c” do acordo, as Partes são guiadas pelo “princípio de controle e redução [...] da poluição, em virtude do qual, as Partes Contratantes buscam aplicar as melhores tecnologias disponíveis e as melhores práticas governamentais em condições econômicas aceitáveis [...]”20, ou o $\S 6^{\circ}$ deste mesmo artigo que dispõe que as Partes protegem, “na medida do possível”, a qualidade do ecossistema do Rio Escaut ${ }^{21}$.

A partir disto constata-se que a proibição geral e absoluta de causar um prejuízo foi susbsituída pela expressão mais flexível do "prejuízo significativo”. Posto isto, a pergunta central sobre o assunto é doravante a do equilíbrio entre a utilização equitável e razoável do curso de água e a possibilidade de causar um prejuízo a este. Devendo ser ressaltado que, de fato, quando há um conflito de utilizações devido à quantidade ou a qualidade da água, nem todos os usos ditos razoáveis e vantajosos podem ser executadas de modo pleno.

A flexibilização da obrigação de não causar danos leva a um resultado mais próximo do que é uma utilização equitável dos recursos, indo além do tratamento do prejuízo transfronteiriço $^{22}$. Por outro lado, a CDI afirma claramente que:

[...] os interesses dos Estados em causa devem ser tomados em consideração de maneira equitável de uns em relação aos outros. Trata-se de levar em consideração não somente o prejuízo causado no absoluto ao Estado vizinho,

\footnotetext{
20 Acordos de Charleville-mézières do 26 de abril de 1994, artigo 3 § 2 'c', disponíveis em $<$ www.diplomatie.gouv.fr/fr/IMG/pdf/escaut.pdf $>$.

21 Acordos de Charleville-mézières do 26 de abril de 1994, artigo $3 \S$ 6, disponíveis em $<$ www.diplomatie.gouv.fr/fr/IMG/pdf/escaut.pdf $>$.

${ }^{22}$ MACCAFREY, S. The Law of International Watercourses, Oxford: Oxford University Press, 2001, p. 355.
} 
mas também a relação entre a vantagem adquirida por um e o prejuízo sofrido pelo outro" ${ }^{23}$. E, "em certas circunstâncias, a utilização equitável e razoável de um curso de água internacional pode ainda causar prejuízos significativos a um outro Estado do curso de água. Geralmente, nestes casos, o princípio da utilização equitável e razoável é o critério determinante para a realização do equilíbrio entre os interesses em jogo ${ }^{24}$.

O posicionamento adotado pela CDI pode ser justificado pela dificuldade existente para a manutenção da vigência da regra de proibição de qualquer espécie de prejuízo. Tal regra pode servir aos Estados de aval como uma arma para paralisar os Estados da parte superior do curso ainda que estes adotem uma utilização equitável e razoável da água. Além disso, qualquer utilização de água causa um certo prejuízo, por conseguinte uma proibição total se mostra extremamente difícil na prática.

Sendo assim, é importante sublinhar, finalmente, que este artigo $7^{\circ}$ da Convenção de 1997, visto como uma obrigação geral de aplicação de diligências para evitar danos significativos, deve ser aplicado em conjunto com a obrigação do artigo 20 desta mesma Convenção, referente à "Proteção e preservação dos ecossistemas”. Essencialmente, esta obrigação de proteção impõe aos Estados que protejam os ecossistemas dos cursos de águas internacionais contra prejuízos ou danos, mesmo que se configurem apenas ameaças. Ressaltando, que, conforme verificado, só os prejuízos significativos à água são contrário às obrigações da Convenção.

2.1.2.2 A obrigação de diligência para não causar danos significativos

De acordo com a CDI:

[...] a obrigação que tem os Estados de tomarem medidas de prevenção ou redução ao mínimo de um risco de prejuízo transfronteiriço significativo é uma obrigação de diligência, que exige deles a adoção de certas medidas unilaterais. A obrigação imposta pelo presente artigo (artigo $7^{\circ}$ da Convenção de 1997) não é uma obrigação de resultado. É o comportamento do Estado que determinará o cumprimento da obrigação que lhe incumbe em virtude dos presentes artigos ${ }^{25}$

\footnotetext{
${ }^{23}$ Nações Unidas, Annuaire de la Commission du Droit International, 1994, vol. 2, p.110.

${ }^{24}$ Nações Unidas, Annuaire de la Commission du Droit International, 1994, vol. 2, p.108.

${ }^{25}$ Do original, "I'obligation qu'ont les Etats de prendre des mesures pour prévenir ou réduire au minimum un risque de dommage transfrontière significatif est une obligation de due diligence, exigeant d'eux qu'ils adoptent à cet effet certaines mesures unilatérales. L'obligation imposée par le présent article n'est pas une obligation de résultat. C'est le comportement de l'Etat qui déterminera s'il s'est acquitté de l'obligation qui lui incombe en vertu des présents articles" Nações Unidas. Annuaire de la Commission du Droit International, 1995, vol. 2, p.120.
} 
O $\S 1^{\circ}$ do artigo $7^{\circ}$ da Convenção de 1997 enuncia a obrigação geral que têm os Estados do curso de água de demonstrarem toda a diligência requerida para utilizar o curso de água internacional de maneira a não causar prejuízos significativos aos outros Estados do curso de água. A diligência requerida pode ser interpretada como "uma diligência proporcional à importância do assunto, dignidade e à força da potência que o exerce e ao cuidado que os governos têm costume de pôr nas matérias que se referem tanto à sua segurança como aos seus nacionais”. ${ }^{26}$

De acordo com a CDI, o Estado não pode garantir que a utilização do curso de água internacional não provocará prejuízo significativo. A diligência é, de fato, uma obrigação de comportamento, e não uma obrigação de resultado.

Ao Estado do curso de água cuja utilização causar um prejuízo significativo não pode ser atribuída uma violação de sua obrigação de exercer diligência requerida para não causar prejuízo significativo a não ser que, de modo intencional ou por negligência, ele não impediu outrem sobre seu território de causar este fato ou se se absteve de o atenuar. Em conseqüência, o Estado poderá ser responsabilizado por não ter tomado as medidas legislativas requeridas, por não ter aplicado as leis, por não ter impedido ou feito parar uma atividade ilegal ou por não ter punido o responsável.$^{27}$

Neste mesmo sentido, a Corte Internacional de Justiça (CIJ) acrescenta no caso "Estreito de Corfu”, que:

[...] não se poderia concluir que o controle exercido por um Estado sobre o seu território terrestre ou sobre as suas águas territoriais é suficiente visto que este Estado pode não ter conhecimento sobre todos os fatos ilícitos perpetrados, assim como os autores dos mesmos. Em si, e independentemente de outras circunstâncias, este fato não justifica nem responsabiliza à primeira vista nem desloca o ônus da prova. ${ }^{28}$

Mas numa outra situação, se apesar do exercício de toda a aplicação requerida na utilização de um curso de água internacional, esta utilização causar prejuízos significativos a outros Estados, o $\S 2^{\circ}$ do artigo $7^{\circ}$ exige que, a menos que exista um acordo sobre esta

\footnotetext{
${ }^{26}$ Do original, “ une diligence proportionnelle à l'importance du sujet, à la dignité et à la force de la puissance qui l'exerce, et le soin que les gouvernements ont coutume de mettre dans les matières qui concernent tant leur sécurité que celle de leurs ressortissants" Caso Alabama (Etats-Unis c. Grande-Bretagne), decisão de 14 de setembro de 1872, Recueil des arbitrages internationaux, t. II, Paris : Pedone, 1923, p.789 e 796.

${ }^{27}$ Do original, “ [...] l'Etat du cours d'eau dont l'utilisation cause un dommage significatif ne peut être réputé avoir manqué à son obligation d'exercer la diligence requise pour ne pas causer des dommages significatifs que si, intentionnellement ou par négligence, il a causé le fait qui aurait dû être prévenu, ou si, intentionnellement ou par négligence, il n’a pas empêché autrui sur son territoire de causer ce fait ou s'est abstenu de l'atténuer. Par conséquent, l'Etat pourra être tenu responsable de n'avoir pas pris les mesures législatives voulues, de n'avoir pas fait appliquer les lois, de n'avoir pas empêché une activité illégale ou de n’y avoir pas mis fin ou de ne pas en avoir châtié le responsable”. Nações Unidas. Annuaire de la Commission du Droit International, 1994, vol. 2, p.109.

${ }^{28}$ Caso do Détroit de Corfou (Royaume-Uni c. Albanie), 1949, Recueil C.I.J., p. 18.
} 
utilização, o Estado cuja utilização causa os prejuízos deverá estabelecer consultas com os Estados do curso de água que tenham sofrido os referidos prejuízos.

Desta forma, percebemos que devem ser analisadas, caso a caso, as diligências tomadas por um Estado frente ao prejuízo causado, a fim de se avaliar a responsabilização pelo mesmo, assim como as medidas a serem adotadas para minimizar os efeitos relativos aos demais.

\subsection{A aplicação das normas materiais}

Uma vez apresentadas as normas materiais, resta a análise da aplicação das mesmas, onde se buscará apresentar tanto a atuação dos Estados na interpretação dos dispositivos em seu uso normal dos cursos de águas internacionais, quanto do juiz, no momento em que é demandado para a determinação do real sentido de dispositivos e princípios muitas vezes abertos e provocadores de interpretações dúbias.

\subsubsection{A atuação dos Estados na aplicação da norma: flexibilidade na interpretação}

Em primeiro lugar, nota-se que a obrigação de utilização equitável e razoável representa um ponto de partida para as negociações entre os Estados que possuem conhecimento de que certas modalidades de distribuição não poderão ser instauradas. Assim, particularmente, a construção de obras de desvio ou exploração da totalidade do recurso por uma delas será excluída prima facie. Isto explica que a doutrina da soberania absoluta não foi invocada por nenhum Estado no momento das negociações da convenção de 1997.

Tal obrigação permite, por conseguinte, a imposição de uma conduta negativa, ao precisar como os Estados não podem pretender utilizar o recurso comum. De fato, o artigo $5^{\circ}$ da Convenção de 1997 busca afastar as doutrinas absolutistas tradicionalmente invocadas, consagrando a todos, mesmo que de modo implícito, a doutrina da soberania limitada, que ao mesmo tempo não determina a repartição das águas de modo igual para todos os Estados que compõem a bacia. Anteriormente, os Estados da parte superior do curso de água internacional invocavam a doutrina da soberania territorial absoluta dita doutrina Harmon elaborada pelos Estados Unidos no século XIX. Segundo tal teoria, a água reside sob a soberania exclusiva do Estado sobre o qual passa. Tal tese favorecia os Estados situados no início do curso de água na medida em que permitia a estes disporem livremente das águas do rio sem consideração de efeito que a sua utilização poderia ter sobre os demais Estados dispostos ao longo do curso. Esta doutrina é ainda conhecida como doutrina da primeira utilização (ou doutrina de "first 
in time, first in right”), que já tinha sido invocada na década de 1890 pelo México no conflito com os Estados Unidos sobre o Rio Grande. ${ }^{29}$ Como o seu nome indica, esta teoria concede um direito prioritário de utilização das águas ao Estado que explorou e valorizou o recurso em primeiro. Entretanto, muito mais favorável a estes Estados de aval é a doutrina da integridade territorial absoluta. Em virtude desta última, os Estados da parte superior têm o direito de utilizar as águas que passam sobre o seu território apenas na condição de não prejudicarem a quantidade e a qualidade da água que passa no território do Estado de aval.

Se estas teorias têm apenas um valor teórico, elas revelam, contudo, as tensões que resultam da existência de um recurso comum. Mais especificamente no âmbito da Convenção de 1997, verifica-se que esta não favoreceu nenhuma das doutrinas expostas. Assim sendo, uma solução sobre a divisão da água parece assim possível apenas na condição de se chegar à elaboração de uma solução mediana baseada numa concepção mais econômica que territorial do recurso aquático. O que se percebe é que a noção de “distribuição equitável e razoável” tem o mérito de afastar certas modalidades de distribuição, mas deixa ainda aos Estados uma liberdade de apreciação muito ampla.

Tal amplitude de apreciação resulta na consideração destas obrigações como flexíveis no sentido de que a obrigação de utilização equitável é necessariamente maleável dado que a distribuição é equitável apenas em um momento “m”. Podendo vir a ser inequitável em um segundo momento “ $m+1$ ”. Desta forma, conclui-se que os acordos de repartição de águas internacionais comuns não podem pretender dispor de modo rígido a distribuição da água entre as partes à maneira dos tratados que são concluídos em outros domínios pelos quais as cláusulas podem ser revistas apenas no caso de mudança fundamental de circunstâncias. ${ }^{30}$. As convenções bilaterais e multilaterais que serão concluídas no futuro deverão, deste modo, obedecer ao sistema estabelecido pela Convenção de 1997, e incluir disposições flexíveis de repartição de águas ou formular cláusulas de revisão da repartição inicialmente acordada.

Em segundo lugar, indica-se que mesmo se o artigo $6^{\circ}$ da Convenção de 1997 visa trazer precisões quanto aos critérios que devem ser considerados para uma divisão equitável

\footnotetext{
29 Documentação referente ao caso "Rio Grande” envolvendo Estados Unidos e México disponível em <http://www.internationalwaterlaw.org/ >.

30 Artigo 62 da Convenção de Viena de 1969 sobre o direito dos tratados: “(Mudança Fundamental de Circunstâncias) 1. Uma mudança fundamental de circunstâncias, ocorrida em relação às existentes no momento da conclusão de um tratado, e não prevista pelas partes, não pode ser invocada como causa para extinguir um tratado ou dele retirar-se, salvo se: a) a existência dessas circunstâncias tiver constituído uma condição essencial do consentimento das partes em obrigarem-se pelo tratado; e b) essa mudança tiver por efeito a modificação radical do alcance das obrigações ainda pendentes de cumprimento em virtude do tratado.”
} 
do recurso, estes se mostram insuficientes. O problema reside no fato de que estes critérios podem ser interpretados pelos Estados de modo a opor seus interesses igualmente legítimos e de mesmo valor jurídico, trazendo por conseqüência choques de interpretações. Exemplo disto foi a repartição do curso de água do Rio grande, em que se observou que com base em critérios diferentes, os Estados Unidos e o México, no momento do litígio ocorrido no fim do século XIX, reclamaram ambos a parte mais importante do recurso comum. O México justificou o seu direito de utilização do recurso com base na utilização anterior que houvesse feito da água ou a sua necessidade econômica. Já os Estados Unidos o fizeram por meio dos critérios geográfico e natural. Considerar todos estes fatores sem estabelecer uma hierarquia entre cada interpretação legítima da obrigação principal leva à impossibilidade de uma solução realista para disputas que envolvam águas internacionais. ${ }^{31}$.

Com efeito, em cada caso a interpretação dos princípios pode ser feita pelas partes de maneira unilateral. No entanto, isto traz conseqüências nefastas para a aplicação destes princípios. Com efeito,

[...] uma regra única pode ser esquartejada entre as várias interpretações, de igual valor jurídico e igualmente presumidas conforme esta regra. Esta concorrência é virtualmente produtora de desordem e incoerência do sistema jurídico internacional. Cada um é assim juiz da sua própria causa, com as conseqüências de ordem unilateral que podem resultar ${ }^{32}$.

Diante deste conflito de interpretações, possuindo todas o mesmo valor e muitas vezes conflitantes pela diversidade de interesses em jogo, surge a figura do juiz, como mediador destes conflitos, sendo fundamental na aplicação dos princípios de utilização das águas dos rios internacionais, a fim de produzir a efetividade necessária para a legitimação e respeito de tais conflitos.

2.2.2 A atuação do juiz na aplicação das normas: a proliferação do contencioso pela busca da efetividade

Diante da problemática da flexibilização das normas orientadoras da repartição das águas internacionais, surge a necessidade de uma entidade capaz de mensurar o real sentido dos dispositivos, assim como a relevância que se deve atribuir aos fatores ou critérios envolvidos.

\footnotetext{
${ }^{31}$ Do original "consideration of all these factors without a method of gauging their relative importance cannot provide conclusive and realistic solutions to disputes over international waters”. WENIG, J. Water and Peace: the Past, the Present and the Future of the Jordan River Watercourse: an International Analysis, New York Journal of International Law and Politics, 1995 (27), p. 348.

${ }^{32}$ COMBACAU, J. Droit international public. Paris : Monchrestien, 6. ed., 2004, p.171.
} 
Uma vez a obrigação posta pela Convenção de 1997 ou pela repartição efetuada através de uma convenção negociada pelas partes, o diferendo eventual que pode nascer no momento da aplicação da obrigação deverá ser resolvido pelo juiz à luz não somente do princípio da distribuição e utilização equitável e razoável do curso de água internacional, mas também à luz do princípio de não causar prejuízos significativos ao curso de água. As partes podem, portanto, como os estados federados dos Estados Unidos ${ }^{33}$ o fazem há muito tempo diante dos juízes de seu estado, contestar a construção da obra ou de outras medidas aplicadas sobre o curso de água por outros estados, caso isto as prive do benefício de utilização equitável e razoável do recurso comum. Distante de serem obrigações rígidas e exaustivas de repartição, conforme verificado, estas obrigações são instrumentos importantes para o juiz que, desde a apreciação, poderá então afastar as utilizações não-equitáveis.

Assim sendo, é a partir da jurisprudência internacional que as obrigações de utilização equitável e razoável e utilização não-prejudicial do território ganham sentido. Com efeito, aos atos unilaterais estatais de repartição e uso das águas são impostas certas limitações sob pena de verem seus atos punidos por uma jurisdição internacional. Neste sentido, percebese que as obrigações da Convenção são úteis ao juiz, como pontos de partida para a determinação da forma, segundo a qual, os Estados não podem proceder. Ou seja, em certa medida, constitui-se uma definição negativa do âmbito de aplicação da utilização equitável e razoável.

Pela leitura das decisões, pode-se depreender que os Estados não podem, em nome da divisão equitável e razoável, assegurar um controle exclusivo do curso de água (em especial quando uma convenção confia a gestão do curso de água a um outro Estado ribeirinho $)^{34}$ ou efetuar trabalhos que privam o outro Estado de uma parte importante das águas sem o seu consentimento. ${ }^{35}$

Mais precisamente, no caso da “Fundição de Trail” envolvendo os Estados Unidos e o Canadá, o Tribunal arbitral não proibiu simplesmente a fundição canadense de conduzir novas operações, pois de fato ela procedeu com um exame do equilíbrio entre os interesses da indústria canadense e a comunidade agrícola americana. O Tribunal levou em consideração a vontade das partes de chegar a uma solução equitável, que foi interpretada como sendo uma solução que permitia a continuação das operações da fundição, mas impôs restrições e

\footnotetext{
${ }^{33}$ Ver mais precisamente New Jersey v. New York, Suprema Corte dos Estados-Unidos, 1931, 283 US 336 ; Nebraska c. Wyoming, Suprema Corte dos Estados-Unidos, 1945, 325 US 589.

${ }^{34}$ Projeto Gabcikovo-Nagymaros (Hongrie/Slovaquie), 1997, Rec. C.I.J

35 Sentença do Tribunal arbitral sobre a Utilização das águas do Lago Lanoux, (França c. Espanha), 1957 ; sentença disponível na R.G.D.I.P., 1958.
} 
limitações para as operações da indústria canadense, que, na medida do possível, buscariam prevenir os prejuízos causados aos Estados Unidos.

No referente à noção de “equitável”, a C.I.J. estatuiu, em matéria de delimitação da plataforma continental, que a equidade não implicava necessariamente em igualdade e que não há limites jurídicos para as considerações que os Estados têm a capacidade de examinar com a finalidade de se certificarem de que aplicarão critérios eqüitativos. O recomendável é o balanço entre todas as considerações relevantes ao contexto e não a criação de um critério anterior que exclua todas as demais considerações. Desta forma, pode e efetivamente ocorrem vários problemas de equilíbrio na mensuração destas considerações que variam de acordo com cada caso. ${ }^{36}$ De acordo com a C.I.J., “[...] o que é equitável e razoável num caso dado depende necessariamente das circunstâncias." ${ }^{37}$.

No que concerne à obrigação de não causar prejuízo significativo, no mesmo caso da Fundição de Trail de 11 de Maio de 1941, foi entendido que:

[...] de acordo com os princípios do direito internacional assim como de acordo com o direito dos Estados Unidos, nenhum Estado tem o direito de utilizar o seu território ou de permitir a utilização de maneira a causar, pela emissão dos fumaça, um prejuízo ao território de um outro Estado, ou a propriedade ou as pessoas que se encontram, caso ocasionem conseqüências sérias e se os prejuízos forem estabelecido por provas claras e convincentes. ${ }^{38}$

Pouco depois da sentença da Fundição de Trail, a C.I.J. seguiu a mesma linha de pensamento no caso do Estreito de Corfu de 1949. No entendimento deste Tribunal, "estas obrigações são fundadas [...] sob certos princípios gerais e bem reconhecidos, como [...] a obrigação, para qualquer Estado, de não deixar utilizar o seu território para os fins de atos contrários aos direitos dos outros Estados”39. Neste último caso, não se abordou o tema da repartição dos rios internacionais, mas é relevante para demonstrar que o direito de um Estado de utilizar o seu território não é absoluto, estando ligado aos dos demais Estados.

Enfim, em todos os casos analisados, verifica-se que o tribunal admite, sob a forma de um obiter dictum, que há uma regra de direito internacional que proíbe aos Estados

\footnotetext{
${ }^{36}$ Plateau continental de la mer du Nord, (République fédérale de l’Allemagne c. Danemark ; République Fédérale de l’Allemagne c. Pays-Bas), 1969, Recueil C.I.J., paragraphe 93.

${ }^{37}$ Plateau continental (Tunisie c. Jamahiriya arabe lybienne), 1982, Recueil C.I.J., paragraphe 72.

${ }^{38}$ Sentence arbitrale de la Fonderie de Trail (Etats-Unis c. Canada), 11 mai 1941, RIAA, 1907, II, p.165.

${ }^{39}$ Affaire du Détroit de Corfou (Royaume-Uni c. Albanie), 1949, Recueil C.I.J., p.22.
} 
de um curso de água internacional de poluir este recurso, pois isto pode prejudicar os demais Estados pelos quais o curso de água passa. ${ }^{40}$

No caso “Gabcikovo-Nagymaros”, a investigação do equilíbrio mostra-se inicialmente fundamental para o C.I.J., visto que a Corte entendeu que:

[...]o desenvolvimento moderno do direito internacional reforçou este princípio (do equilíbrio da utilização) igualmente para as utilizações dos cursos de águas internacionais para fins que vão além da navegação como atestado pela Convenção de 1997. Posto isto, o Tribunal considerou que, [...] a Tchecoslováquia, tomando unilateralmente o controle de um recurso compartilhado, e privando assim a Hungria do seu direito à uma parte equitável e razoável dos recursos naturais do Danúbio [...] não respeitou o direito internacional ${ }^{41}$.

Contudo neste caso a Corte aparenta ter ido além, visto que considerou que "a obrigação geral que têm os Estados de velar para que as atividades exercidas nos limites de sua jurisdição ou sob o seu controle respeitem o meio ambiente de outros Estados ou de zonas que não pertencem a nenhum órgão jurisdicional nacional faz agora parte do corpo de regras do direito internacional do meio ambiente”. ${ }^{42}$ Além disso, “as partes [...] devem encontrar em comum acordo uma solução que leve em consideração o objetivo do tratado - que deve ser atingido de modo conjunto e integrado - assim como as normas de direito internacional ambiental e princípios de direito relativo ao curso de água internacional”. A Corte afirma ainda que:

[...] o restabelecimento do regime conjunto refletirá também de maneira ótima o conceito de uma utilização conjunta dos recursos de água compartilhados para atingir os diferentes objetivos mencionados no tratado e, em conformidade com o $\S 2^{\circ}$ do artigo $5^{\circ}$ da Convenção sobre o direito relativo às utilizações dos CURSOS DE ÁGUAS INTERNACIONAIS para fins além da navegação [...]. ${ }^{43}$

Enfim, pela apresentação das normas de direito material e a aplicação das normas pelos Estados e pelo juiz, pode-se constatar que as obrigações materiais postas pelo direito internacional geral permitem certamente afastar qualquer utilização de argumentos que invoquem a soberania absoluta dos Estados na utilização dos cursos de águas internacionais. Entretanto, a repartição equitável e razoável destas águas e o uso de modo a evitar prejuízos

${ }^{40}$ CAFLISCH, L. Règles générales du droit des cours d'eaux internationaux. In : Recueil des Cours de l'Académie de Droit International de la Haye, 1989, VII, p.166.

41 Projet Gabcikovo-Nagymaros (Hongrie/Slovaquie), 1997, Recueil C.I.J., p. 56 par. 85.

${ }^{42}$ Projet Gabcikovo-Nagymaros (Hongrie/Slovaquie), 1997, Recueil C.I.J., p.41, par. 53.

43 Projet Gabcikovo-Nagymaros (Hongrie/Slovaquie), 1997, Recueil C.I.J., p.55, par. 147. 
substanciais aos demais Estados resta sem uma definição precisa, mesmo existindo o papel do juiz como mediador e definidor destes critérios. Até porque, vale ressaltar que a utilização do órgão judicial para a composição do conflito deve ser feita em último caso, mas percebe-se que o recurso a este tem sido cada vez mais corrente. Associado a isto, existe a possibilidade de que as partes tomem consciência destes elementos somente no momento da intervenção do juiz, podendo este momento já ser tarde, tendo em vista que um mal uso da água, pode implicar em perdas irreparáveis.

Diante da margem de interpretação destas normas materiais, que conforme se demonstrou trazem por conseqüência a proliferação do recurso às vias judiciais e o risco de uma má utilização irreparável, a Convenção de 1997 desenvolveu a noção de cooperação, que oferece às partes os meios para administrarem este recurso comum, interpretando as normas materiais, sem a necessária intervenção de um terceiro. Isto reforça a efetividade de tais dispositivos principalmente porque pelo princípio da cooperação, os riscos de um mal uso, assim como um entendimento do que é uma repartição equitável e razoável podem ser melhor mensurados pelos próprios Estados. A cooperação, neste sentido, deixa ao juiz um papel secundário, que é útil somente nas situações em que esta cooperação não for possível pelo peso dos interesses em jogo.

\section{Instrumentos utilizados para o alcance da efetividade das normas relativas à utilizaçao dos cursos de agua internacionais}

\subsection{A busca da efetividade das normas a partir do princípio da cooperação}

\subsubsection{A busca da efetividade das normas materiais}

Conforme verificado na primeira parte deste estudo, as normas materiais relativas a utilização e a repartição das águas internacionais são ineficazes. Isto porque a abertura oferecida aos Estados em relação à interpretação e aplicação dos dispositivos implica em contradições que levam ao enfraquecimento da efetividade destes dispositivos. A solução para este problema é o estabelecimento do juiz enquanto mediador. Entretanto, novas problemáticas surgiram com a proliferação dos conflitos e a utilização da via judicial no lugar de soluções negociadas. Considerando que no meio internacional soluções pacíficas são sempre preferíveis a conflitos judiciais.

A imprecisão dos termos e princípios relacionados ao tema pode acarretar a ausência de efetividade dos dispositivos, que por sua vez representa um perigo para todo o 
sistema normativo relacionado, sendo necessária a utilização de novos instrumentos para que esta efetividade não seja totalmente perdida e todo o sistema enterrado.

\subsubsection{A possibilidade das normas materiais não serem efetivas}

A falta de efetividade das normas referentes aos cursos de águas internacionais implica em um risco de falência de todo o sistema regulador deste recurso natural, gerando uma utilização ilimitada e um conflito generalizado quanto à sua repartição. Isto acarreta prejuízos irreparáveis a todo o curso de águas e ao ecossistema relacionado ao mesmo.

Com base na análise das normas feita na primeira parte deste estudo, constata-se que no caso do direito da utilização dos cursos de águas internacionais, o legislador construiu os dispositivos com base em termos e princípios imprecisos, prevendo, deste modo, a dificuldade de sua aplicação. Assim sendo, o legislador inseriu expressamente no próprio sistema a importância e o papel do princípio da cooperação como forma de amenizar as imprecisões do mesmo, conforme será verificado mais adiante.

Entretanto, deve-se compreender que a falta de efetividade das normas relativas a um determinado curso de água representa ao mesmo tempo um perigo para todo o ecossistema que circunda este, assim como para sua qualidade e para a população que habita as margens deste. Logo, percebe-se que os governos devem estar interessados na busca pela maior efetividade de tais regramentos, visto que isto amenizará o perigo de perdas dos agentes diretamente ou indiretamente ligados ao curso.

\subsubsection{Efetividade pela precaução}

Partindo da compreensão da possível falta de efetividade de todo o aparato jurídico que regula a utilização e repartição dos cursos de águas internacionais em razão da utilização de termos e princípios vagos e imprecisos, verifica-se que o próprio legislador estabeleceu mecanismos de precaução contra esta situação.

Isto porque se verifica que caso o sistema se mostre constantemente inefetivo, pode vir a perder o respeito e a legitimidade no contexto internacional, tornando esta ausência de efetividade um fenômeno irreparável. Sendo assim, antes que todo o sistema simplesmente passe a ser desacreditado em virtude da falta de efetividade de seus termos e princípios, necessitando de mecanismos de reparação como novos acordos e mesmo emendas, o 
legislador definiu o princípio da cooperação como uma espécie de princípio da precaução para o sistema legal regulador dos cursos de águas internacionais.

O princípio da precaução pode ser definido como aquele utilizado em situações segundo a qual a falta de certeza, não devem ser posta como obstáculo para a adoção ou demora na adoção de medidas preventivas ${ }^{44}$. Vale ressaltar que este é um princípio correntemente utilizado no âmbito do direito ambiental, sendo expressamente previsto na Declaração do Rio sobre o meio ambiente e desenvolvimento de 1992:

[...] para proteger o meio ambiente, medidas de precaução devem ser amplamente aplicadas pelos Estados segundo sua capacidade. Em caso de risco de danos graves ou irreversíveis, a ausência de certeza científica absoluta não deve servir de pretexto para retardar a adoção de medidas efetivas visando prevenir a degradação do meio ambiente. ${ }^{45}$

Desta forma, transferindo a essência deste princípio para a atuação do legislador nas normas referentes aos cursos de águas internacionais, compreende-se que o princípio da precaução foi o ponto de partida para que o princípio da cooperação funcione como base de efetividade para os demais dispositivos. Entretanto, conforme será verificado, este princípio da cooperação necessita de um instrumento para ser aplicado, papel exercido pelas Comissões Internacionais, tema da próxima seção.

\subsubsection{O princípio da cooperação}

Funcionando como um princípio necessário para a gestão de uma possível falta de efetividade das normas materiais utilizadas para repartição e utilização dos cursos de águas internacionais, a obrigação de cooperar tem sentido em direito internacional apenas se for cercada por obrigações específicas como a de informar e notificar os demais Estados do curso de água internacional. Nota-se que esta obrigação ganhou uma importância essencial, principalmente no funcionamento das Comissões de gestão dos cursos de águas internacionais. Tais comissões devem o seu sucesso ao fato de que são elaboradas e geridas pelos principais interessados na repartição e utilização deste recurso, ou seja, os próprios Estados.

\subsubsection{Uma obrigação geral de cooperar cercado das obrigações auxiliares}

\footnotetext{
${ }^{44}$ SALMON, J. Dictionnaire de droit international public. Bruxelas: Bruylant, 2001, p. 865.

${ }^{45}$ Princípio n ${ }^{\circ} 15$ da Declaração do Rio sobre o meio ambiente e desenvolvimento de 14 de junho de 1992.
} 
A cooperação entre os Estados é fundamental para uma boa utilização e gestão dos cursos de águas internacionais. Na decisão sobre o Lago Lanoux, a Corte afirmou que os Estados atualmente já têm consciência da importância dos interesses contraditórios que prejudica a utilização industrial dos rios internacionais, assim como da necessidade de conciliar uns aos outros através de concessões mútuas e que o único modo para a condução e esta conciliação de interesses reside no estabelecimento de acordos, sobre uma base cada vez mais compreensiva. Desta forma, a prática internacional demonstra a convicção de que os Estados devem buscar concluir tais acordos. ${ }^{46}$.

A C.I.J. seguiu esta lógica e, em 1974, no caso da "Competência em matéria das pescarias”, deliberou sobre a obrigação de negociar, afirmando que o método mais próprio de resolver o diferendo é obviamente o da negociação. “O seu objetivo deve ser o de limitar os direitos e os interesses das partes e que a obrigação de negociar decorre, por conseguinte, da natureza mesmo dos direitos respectivos das partes e corresponde aos princípios e as disposições da Carta das Nações Unidas relativos ao regulamento pacífico dos diferendos. A tarefa das partes será a de conduzir as suas negociações num espírito tal que cada uma deva, de boa fé, ter em conta razoavelmente os direitos do outro, dos tratamentos da situação local, tomando em considerações os interesses de outros Estados que têm direitos estabelecidos”. ${ }^{47}$ A recente decisão Gabcikovo-Nagymaros é ainda mais explícita quanto ao dever de cooperar, pois, segundo a Corte, as medidas destinadas a atenuar os problemas do Danúbio "só poderiam ser tomadas no âmbito de uma cooperação internacional”. ${ }^{48}$

A importância da cooperação para a utilização dos cursos de águas internacionais e outros recursos naturais comuns foi diversas vezes sublinhada em declarações ou resoluções adotadas por organizações internacionais, conferências e reuniões intergovernamentais. Ressalta-se a Carta dos Direitos e Deveres Econômicos dos Estados (Resolução 3281 XXIX da Assembléia geral), que no seu preâmbulo dispõe que "no exercício da sua soberania sobre os seus recursos naturais, os Estados devem esforçar-se, através de uma cooperação bilateral e multilateral eficaz ou de mecanismos regionais, para a proteção e melhoria do meio ambiente”, no mesmo sentido do disposto no princípio 24 da Declaração de Estocolmo de

\footnotetext{
${ }^{46}$ Sentença do Tribunal Arbitral, caso Lago Lanoux, (França c. Espanha), 16 de novembro de 1957, par.11. Sentença disponível na R.G.D.I.P., 1958, p.79 e seguintes.

${ }^{47}$ Compétence en matière des pêcheries (Royaume-Uni c. Islande), mérito, 1974, Recueil C.I.J, p. 31 à 33, § 73, 75 et 78.

48 Do original, “ne pouvaient être prises que dans le cadre d'une coopération internationale”. Projet Gabcikovo-Nagymaros (Hongrie/Slovaquie), 1997, Recueil C.I.J., p. 18-19, paragraphe 17.
} 
1972. As Resoluções 2995 XXVII (sobre a cooperação entre os Estados no domínio do meio ambiente) e 3129 XXVIII (sobre a cooperação no domínio do meio ambiente em matéria de recursos naturais compartilhados por dois ou vários Estados) seguem esta mesma linha de pensamento.

De modo mais específico, a utilização desta obrigação de cooperar pode ser percebida, em relação aos cursos de águas internacionais, a partir de 1944, no tratado entre os Estados Unidos e o México sobre a utilização do Rio Grande ${ }^{49}$. Todavia, esta obrigação de cooperar mostra-se mais direta em tratados recentes como nos Acordos Charleville-Mézières de 1994 sobre a utilização do rio Meuse que dispõem, no artigo $2^{\circ} \S 1^{\circ}$, que “os signatários [...] comprometem-se a cooperar a fim de preservar e melhorar a qualidade do rio Escaut e Meuse". ${ }^{50}$

Mas é a Convenção de Nova Iorque de 1997 que erigiu explicitamente esta obrigação de cooperar como princípio geral da utilização dos cursos de águas internacionais. Esta obrigação de cooperar mostra-se, com efeito, fundamental, se os Estados querem realizar uma utilização equitável das águas, assegurando vantagens a todos, além de uma boa aplicação das regras de procedimento estabelecidas.

\subsubsection{A aplicação do princípio da cooperação}

A obrigação de cooperar não deve ser entendida como uma obrigação abstrata, devendo ser estudada na prática internacional ${ }^{51}$, visto que a partir de um princípio geral de cooperação surgem obrigações precisas para os Estados.

Não se estabelecerá, no âmbito deste estudo, uma lista exaustiva sobre essas obrigações secundárias, mas serão apresentadas algumas obrigações consideradas como principais. Assim sendo, no que diz respeito à Convenção de 1997, esta, em seu artigo 3, permite aos Estados concluir acordos sobre os cursos de água, devendo ser aplicadas as disposições do tratado relativas às utilizações e características específicas de tal curso de água. O artigo $5^{\circ}$ da mesma Convenção afirma que a utilização equitável e razoável comporta ao mesmo tempo o direito de utilizar o curso de água e o dever de cooperar à sua proteção e valorização. Nos termos do artigo 8, “os Estados do curso de água cooperam com base na

\footnotetext{
${ }^{49}$ Tratado entre os Estados Unidos e o México sobre o Rio Grande, 3 de fevereiro de 1944, artigo 2, disponível em: <www.ibwc.state.gov/Files/1944Treaty.pdf $>$.

50 Acordos de Charleville-mézières do 26 de abril de 1994, artigo $2 \S$ 1, disponíveis em: $<$ www.diplomatie.gouv.fr/fr/IMG/pdf/escaut.pdf $>$.

${ }_{51}$ MACCAFREY, S. The Law of International Watercourses. Oxford: Oxford University Press, 2001, p. 398.
} 
igualdade soberana, da integridade territorial e a vantagem mútua para chegar à utilização ótima e a proteção adequada do curso de água internacional”.

Associado a isto, o artigo $9^{\circ}$ da Convenção de 1997 afirma que este princípio geral de cooperar é a base da troca regular de dados e de informações, essencial para assegurar uma utilização equitável e razoável de um curso de água internacional. Com efeito, as informações regulares são essenciais para que os Estados estejam de acordo com as demais obrigações previstas principalmente nos artigos $4^{\circ}, 5^{\circ}$ e $6^{\circ}$ da Convenção. Por outro lado, o artigo $11^{\circ}$ enuncia uma obrigação geral dirigida aos Estados do curso de água: estes devem comunicar uns aos outras informações relativas aos efeitos eventuais, sobre o estado do curso de água internacional e das medidas que pretendem colocar em prática. A prática estatal segue esta obrigação de informação, principalmente nos recentes Acordos Charleville-Mézières, que num artigo $4^{\circ}$ sobre a qualidade do fundo do curso de água, indicam que os signatários, com o propósito da proteção do rio, dispõem informações recíprocas a respeito de sua política relacionada à gestão dos sedimentos deste ${ }^{52}$.

Além disso, o artigo $12^{\circ}$ da Convenção de 1997 impõe a obrigação de notificar medidas projetadas e que podem causar um efeito negativo sobre o curso água internacional. A CDI, nos trabalhos preparatórios da Convenção de 1997, justifica essa obrigação secundária afirmando que este princípio de notificação está previsto em diversos acordos internacionais, decisões de Cortes e tribunais internacionais, declaração e resoluções, conferências e reuniões", oferecendo diversos exemplos práticos desta prática ${ }^{53}$. Com efeito, esta obrigação de notificação mostra-se essencial pelo fato de que parece ser insuficiente, para resolver conflitos sobre os cursos de água, a simples apresentação de "uma lista de critérios para a aplicação unilateral por parte dos Estados interessados” ${ }^{44}$. Com efeito, o conflito pode ser evitado negociando e compartilhando-se as informações. Para esse efeito, é importante

52 Acordos de Charleville-mézières do 26 de abril de 1994, artigo 4 § 1, disponíveis em: $<$ www.diplomatie.gouv.fr/fr/IMG/pdf/escaut.pdf. $>$.

53 Nações Unidas. Annuaire de la Commission du Droit International, 1994, vol. 2, p.118. A título de exemplo, a CDI cita o estatuto do Rio Uruguai de 1975, adotado pelo Uruguai e pela Argentina; o regime convencional que rege o rio Niger ; XXXXle régime conventionnel régissant le fleuve Niger ; le traité du 19 novembre 1973 entre l'Argentin et l'Uruguay relatif au Rio de la Plata et à son front maritime ; la décision arbitrale Lac Lanoux de 1951 ; la Déclaration de Montevideo adoptée dans la septième Conférence internationale des Etats américains ; les Règles de Helsinki ; les articles sur la "Régulation du débit d'eau internationaux »; les « Règles sur la pollution des eaux d’un bassin de drainage international », adoptées par l’ILA en 1982. De plus, la CDI tient à souligner que « la liste ci-dessus des sources n'est pas exhaustive, mais elle suffit à montrer quelle importance les Etats et les organes d'experts attachent au principe de la notification préalable des mesures projetées.

${ }^{54}$ HIGGINS. R. Problems and Process : International law and how we use it. Oxford: Oxford University Press, 1994, p.134. 
sublinhar que o texto do CDI requer a distribuição de todas os tipos de informação técnica, assim como os planos intencionados pelos Estados.

Já o artigo 20 da Convenção de 1997, reconhece que, em certos casos, é indispensável e até mesmo adequado que os Estados do curso de água cooperem entre si, sob uma base equitável, visando a proteção e preservação dos ecossistemas dos cursos de águas internacionais. Neste mesmo sentido dispõe a CDI, afirmando que as "medidas devem ser tomadas conjuntamente e em cooperação quando cabíveis e que devem possuir uma base equitável” [...] e que “o que constitui medidas concebidas sobre uma base equitável variará evidentemente em função das circunstâncias”. 55

\subsection{A instrumentalização para o alcance da efetividade das normas materiais}

\subsubsection{A importância da instrumentalização}

Verificada a possibilidade de uma falta de efetividade das normas utilizadas para a utilização das águas internacionais, constatou-se que o princípio da cooperação pode servir aos Estados como uma base sob a qual eles interpretam tais normas, reforçando a efetividade das mesmas. Todavia, mesmo sendo o princípio da cooperação um importante elemento para o alcance desta efetividade, deve ocorrer um trabalho de instrumentalização para que os Estados trabalhem em conjunto na busca pelo real sentido dos dispositivos e gestão ótima dos cursos de águas internacionais.

Pelo estudo das normas materiais, nota-se que o ponto mais crucial para o fortalecimento de sua efetividade é a interpretação das mesmas. Isto pode ser confirmado, pelo recurso crescente às vias judiciais, na busca do real sentido dos dispositivos. Afinal, não basta apenas receber e buscar a decodificação do dispositivo criado pelo legislador, deve haver um ente com legitimidade para mensurar cada um destes elementos. Além disso, neste trabalho de interpretação deve ser levado em consideração os riscos potenciais de uma falta de efetividade da mesma, visto que isto implica em falência de todo o sistema. Neste ponto compreende-se o importante papel deste instrumento organizacional com poderes para adotar linhas de interpretação que podem repercutir em todos os campos envolvidos, indo desde o jurídico até o econômico, político e social ${ }^{56}$.

\footnotetext{
${ }^{55}$ Nações Unidas. Annuaire de la Commission du Droit International, 1994, vol. 2, p.124.

${ }^{56}$ GIDDENS, A.; BECK, U.; LASH, S. Modernização reflexiva: política, tradição e estética na ordem social moderna. São Paulo: UNESP, 1997, p. 111.
} 
Na busca por esta instrumentalização, comitês, conselhos de participação, conferências e consultas são as instituições mais utilizadas em suas diversas formas de atuação. Tais órgãos são responsáveis pela verificação das normas materiais em si, devendo zelar pela efetividade das mesmas, ou seja, oferecer interpretações que amenizem os efeitos adversos de um mal entendido em relação a algum termo ou dispositivo. Verificando-se a amplitude da criação legal, a instrumentalização oferecida para o alcance da efetividade de tais normas efetuará um trabalho de avaliação e busca pelo real sentido da mesma. Além disso, a interpretação feita por tais órgãos vinculará todos os agentes com ele relacionados, reforçando ainda mais a importância e responsabilidade de sua atuação.

Por fim, deve se considerar que o risco de que as normas de direito material referente aos cursos de águas internacionais não sejam efetivas estará sempre presente, sendo de certo modo aceitável diante do desafio que representa a administração de um rio que passe por diversos territórios, significando diferentes soberanias e interesses. Todavia, esta instrumentalização através de órgãos competentes para interpretar os dispositivos e minimizar os conflitos de entendimento sobre os mesmos é fundamental para o alcance da efetividade dos mesmos. Tais órgãos ditam formas de comportamento aos Estados, definindo de modo implícito valores comuns a guiarem a repartição e utilização dos rios de modo equitável, razoável e sem causar danos substanciais.

\subsubsection{As Comissões como instrumentalização para uma real efetividade das normas materiais}

A obrigação de cooperação decorre de uma prática proveniente de uma gestão integrada de recursos. Em relação aos Acordos Charleville-Mézières de 26 de Abril de 1994, verifica-se que mesmo que os Estados signatários não tenham entrado em um consenso sobre a organização, pelo menos não de imediato, de uma gestão comum, isto não impediu a instituição, para o Rio Escaut como para o Rio Meuse, de uma “Comissão Internacional” que é, por excelência, o instrumento de auxílio proposto para o exercício de seus deveres de cooperação visando a proteção e a melhora da qualidade dos rios, deveres outrora já estabelecidos pelo direito internacional do meio ambiente. ${ }^{57}$

De fato, o artigo $2^{\circ} \S 2^{\circ}$ do Acordo dispõe que "para as necessidades da cooperação internacional sobre o Escaut, as Partes criam uma Comissão Internacional para a

\footnotetext{
${ }^{57}$ VERHOEVEN, J. “Les accords de Charleville-Mézières du 26 avril 1994 sur l’Escaut et sur la Meuse”. In : Annuaire Français de Droit International, 1997, p.806.
} 
proteção do Escaut contra a poluição" ${ }^{58}$. O artigo $5^{\circ}$ do Acordo indica as missões desta Comissão que devem ser compostas pelas delegações das partes contratantes. Esta Comissão constitui:

[...] sobretudo o lugar onde as partes pedem, trocam ou organizam informações indispensáveis para proteger ou melhorar a qualidade das águas, prepara, propõe, coordena ou avalia os programas ou políticas adotadas para esse efeito, e principalmente, completa ou desenvolve as cooperações requeridas para os mesmos fins ${ }^{59}$

Este tipo de Comissão não é de modo algum novo no cenário internacional. Os Estados Unidos e o México também estabeleceram uma comissão para o Rio Grande no tratado de 1944, chamada Internacional Boundary Comission, que possuía como principal objetivo a facilitação da realização das obrigações previstas no tratado de $1944 .{ }^{60}$

Assim sendo, esta organização inter-governamental deve ser portadora de uma dinâmica capaz de produzir um consenso na identifição das diretrizes de ação comuns a todos os Estados. A consequência direta do estabelecimento dessas comissoes seria uma harmonização do comportamento dos diversos parceiros transfronteiriços o que contribue diretamente na transparência e na coordenação da gestão de um curso de agua internacional.

A Convenção de 1997 possibilita, por conseguinte, o estabelecimento de certas obrigações de cooperação para evitar a ocorrência de litígio entre os Estados ribeirinhos. Contudo, no caso de fracasso da aplicação das obrigações procedimentais, os procedimentos comuns de regulamento dos litígios intervirão para restabelecer as obrigações materiais e a cooperação entre as partes.

Artigo recebido em março de 2007

Aceito para publicação em abril de 2007

\section{Referências}

\footnotetext{
${ }^{58}$ Accords de Charleville-mézières du 26 avril 1994, article 2 § $\quad 2$, disponível em : $<$ www.diplomatie.gouv.fr/fr/IMG/pdf/escaut.pdf .>.

59 VERHOEVEN, J. “Les accords de Charleville-Mézières du 26 avril 1994 sur l’Escaut et sur la Meuse”. In : Annuaire Français de Droit International, 1997, p.808.

60 Traité entre les Etats-Unis et le Mexique du 3 février 1944 sur le Rio Grande, article 2, disponível em : $<$ www.ibwc.state.gov/Files/1944Treaty.pdf $>$.
} 
AARGAU C. ZURICH. Cour fédérale de Suisse, 1878, Entscheidendungen des Schweizerischen Bundesgerichts, vol. 14 (1), p. 442.

Accord de Charleville-Mezière du 26 avril 1994 entre la République Française, le Royaume des Pays-Bas, de la Région Wallonne, de la Régions Flamande, de la Région BruxellesCapitale.

BARROSO, L. O Direito Constitucional e a Efetividade de suas Normas: limites e possibilidades da Constituição Brasileira. 7. ed, Rio de Janeiro: Renovar, 2003,

BROMS, B. Natural Resources, sovereignty over. In: BERNHARDT, R. Encyclopaedia of Public International Law, vol. 3, 1997, pp. 521-533.

CAFLISCH, L. La convention du 21 mai 1997 sur l'utilisation des cours d'eau internationaux à des fins autres que la navigation. In : Annuaire français de droit international, 1997, pp. 725-767.

Règles générales du droit des cours d'eaux internationaux. In : Recueil des

Cours de l'Académie de Droit International de la Haye, 1989, VII, pp. 1- 200.

CASO ALABAMA. (Etats-Unis c. Grande-Bretagne), 14 septembre 1872. Recueil des arbitrages internationaux, t. II, Paris, Pedone, 1923, p.789 et 796.

CASO DO DETROIT DE CORFOU (Royaume-Uni c. Albanie), 1949, Recueil C.I.J.

COMBACAU, J. Droit international public. 6. ed, Paris : Monchrestien, 2004.

COMPETENCE EN MATIERE DES PECHERIES (Royaume-Uni c. Islande), mérito, 1974, Recueil C.I.J.

Convention des Nations unies sur le droit d'utilisation des cours d'eau internationaux à des fins autres que la navigation, du 21 mai 1997.

Convention entre les Etats-Unis et le Mexique concernant la distribution équitable des eaux du Rio Grande pour l’irrigation, 1906.

DECISÃO DO TRIBUNAL ARBITRAL SUR L'UTILISATION DES EAUX DU LAC LANOUX (France c. Espagne), 1957. Sentença disponível na R.G.D.I.P., 1958.

Déclaration de Stockholm sur l'environnement, issue de la Conférence des Nations unies sur l'environnement, 1972

FITZMAURICE, M. The Gabcikovo-Nagymaros Case: The Law of Treaties. In: Leiden Journal of International Law, 1998, pp. 300-321.

FUENTES, X. The Criteria for Equitable Utilization of International Rivers. In: British Yearbook of International Law, 1996, pp. 1-40.

GERVAIS, F.J. Affaire du Lac Lanoux, Etude critique de la sentence du tribunal arbitral. In : Annuaire français du droit international, 1960, pp. 361-377. 
GIDDENS, A.; BECK, U.; LASH, S. Modernização reflexiva: política, tradição e estética na ordem social moderna. São Paulo: UNESP, 1997.

HIGGINS, R. Problems and Process : International law and how we use it. Oxford: Oxford University Press, 1994.

JURIDICTION TERRITORIALE DE LA COMMISSION INTERNATIONALE DE L'ODER (Tchécoslovaquie, Danemark, France, Allemagne, Royaume-Uni, Suède, Pologne), 1929, CPIJ, Série A, arrêt nº 23.

KISS, A. BEURIER, J-P. Droit International de l'Environnement. Paris : Pedone, 2004.

LE DETOURNEMENT DE L’EAU DE LA MEUSE (Pays-Bas c. Belgique), 1937, CPIJ, Série A/B, arrêt $n^{\circ} 81$.

LUHMANN, Niklas. Risk. A sociological theory. Berlin: De Gruyter, 1993.

MACCAFREY, S. The Law of International Watercourses. Oxford: Oxford University Press, 2001.

MELLO, M. Teoria do Fato Jurídico: plano da validade. 3. ed., vol. 1, São Paulo: Saraiva, 1999,

NAÇÕES UNIDAS. Annuaire de la Commission du Droit International, 1994, vol. 2.

NAÇÕES UNIDAS. Annuaire de la Commission du Droit International, 1995, vol. 2.

NEBRASKA C. WYOMING, Cour suprême des Etats-Unis, 1945, 325 US 589.

NEW JERSEY V. NEW YORK, Cour suprême des Etats-Unis, 1931, 283 US 336.

NOIVILLE, Christine. Du bom gouvernement des risques. Le droit et la question du « risque acceptable ». ? Ed., Paris :Presses Universitaires de France, 2003.

PLATEAU CONTINENTAL DE LA MER DU NORD, (République fédérale de l'Allemagne c. Danemark ; République Fédérale de l’Allemagne c. Pays-Bas), 1969, Recueil C.I.J. PLATEAU CONTINENTAL (Tunisie c. Jamahiriya arabe lybienne), 1982, Recueil C.I.J. PROJET GABCIKOVO-NAGYMAROS (Hongrie/Slovaquie), 1997, Recueil C.I.J.

Règles d’Helsinki sur l’utilisation des eaux des rivières internationales, 1966

SALMON, J (dir.). Dictionnaire de droit international public. Bruxelas : Bruylant, 2001.

SANDS, Ph. Principles of International Environmental Law. Cambridge: Cambridge University Press, 2003, p. 497.

SENTENÇA ARBITRAL DA FONDERIE DE TRAIL (Etats-Unis c. Canada), 11 mai 1941, RIAA, 1907, II. 
SETTE-CAMARA, J. Pollution of International Rivers. In : Recueil des Cours de l'Académie de Droit International de la Haye, 1984, vol. 3.

Traite Entre La Belgique Et Le Pays Bas « pour régler de façon permanente définitivement le régime du détournement de l'eau de la Meuse pour l'alimentation des canaux de navigation et d'irrigation », 1863.

Traité entre les Etats-Unis et le Mexique concernant l'utilisation des eaux du Colorado, Tijuana et du Rio Grande a partir du Fort Quitman, Texas, jusqu'au Golfe du Mexique, du 3 février 1944.

VERHOEVEN, J. Les accords de Charleville-Mézières du 26 avril 1994 sur l'Escaut et sur la Meuse. In : Annuaire Français de Droit International, 1997, p.799-809.

WENIG, J. Water and Peace: the Past, the Present and the Future of the Jordan River Watercourse: an International Analysis. In: New York Journal of International Law and Politics, 1995, pp. 330-355.

\section{Resumo}

O presente artigo estudará a efetividade dos instrumentos jurídicos internacionais que governam a utilização e a repartição dos rios internacionais. Em um primeiro momento, constatar-se-á, um fenômeno de proliferação de um contencioso que buscará a efetividade destas normas. Face a ineficácia deste contencioso, em um segundo momento, analisar-se-á os novos instrumentos utilizados na busca da efetividade destas mesmas normas. Esses novos instrumentos são tanto de caráter legal, como a utilização do princípio da cooperação para interpretação dos dispositivos normativos, quanto institucionais, como a implementação das Comissões Internacionais.

Palavras-chave: Efetividade. Rios internacionais. Contecioso internacional.

\begin{abstract}
This article studies the effectiveness of international legal instruments that govern the use and the distribution of international watercourses. In the first place, we will study the phenomenon of the proliferation of a litigation that seeks the effectiveness of these norms. Due to the inefficacy of this litigation, we will analyze new instruments that pursue the effectiveness of theses norms. These new instruments are legal, such as the use of the principle of the cooperation for interpretation of the normative devices, or institucional, such as the implementation of International Commissions.
\end{abstract}

Keywords: Normativity, Effectiveness, International watercourses, International litigation . 